\title{
Students' Perceptions of the use of a YouTube channel specifically designed for an Academic Speaking Skills Course
}

\author{
Seher Balbay a * (D), Selcan Kilis ${ }^{b}$ \\ a Middle East Technical University, Ankara, Turkey \\ ${ }^{b}$ Giresun University, Giresun, Turkey
}

Received 19 July 2017 | Received in revised form 28 September 2017 | Accepted 8 October 2017

\begin{abstract}
Advancements in information and communication technology have revolutionized the notion of teaching and learning in terms of strategies, context, and methods. One of the most remarkable tools used in teaching and learning in the 21st century is YouTube, especially in language education. The literature demonstrates the need for elaboration of the use of YouTube in university level language skills education settings. In the 2016-2017 academic year a YouTube channel with a variety of supplementary material videos, was used in the Academic Speaking Course offered to all departments at Middle East Technical University, Ankara, Turkey. The channel has course-related content input, sample presentations and tasks displaying the expectations of the course, in addition to conversation opening content. This study aims to investigate students' experiences and perceptions towards the use of this YouTube channel. The study was conducted on 70 students taking the compulsory Academic Speaking Skills course offered to students from varying disciplines in Middle East Technical University. Students were asked to fill out a Google Sheets survey at the end of the course on their perceptions on the benefits and drawbacks of the aforementioned YouTube channel. The data was analyzed based on both descriptive statistics and deductive content analysis. The results indicated that the majority of the students benefited to a large extent from the videos on the playlists of this specifically-designed supplementary material YouTube channel. The findings can contribute to further guiding university language instructors by suggesting the abundance of alternative ways to benefit from YouTube and similar online video source platforms.
\end{abstract}

(C) 2017 EJAL \& the Authors. Published by Eurasian Journal of Applied Linguistics (EJAL). This is an open-access article distributed under the terms and conditions of the Creative Commons Attribution license (CC BY-NC-ND) (http://creativecommons.org/licenses/by-nc-nd/4.0/).

Keywords: YouTube; tailor-made playlists; online videos; academic presentations; language education

\section{Introduction}

\subsection{The wind of change in education}

Technology has entered every walk of our lives. In most of the revolutionized classrooms of today one can observe smartboards, or at least projectors and computers becoming indispensable. Moreover, teaching and learning is not limited to physical

\footnotetext{
* Seher Balbay. Tel.: +90-505-257-9208

E-mail address: seherb@metu.edu.tr
} http://dx.doi.org/.. 
schools and classrooms today. We are in an age where smart phones are the source of either information directly, or guidance when needed for our digitally-oriented young adult students at universities. This being the case, in this digital era, it is not surprising that the literature has repeatedly focused on the motivational effects of the uses of online technology, in language classrooms, as well as the practical solutions of giving feedback on students' performance or progress especially through the use of Web 2.0 tools. So, today, the responsibility of a language teacher is to make the most efficient use of these tools, this technology in general, that is available. Among these tools, videos play a major role in language classrooms. The use of videos became popular in the beginnings of the 21st century as students started spending more time with audiovisuals than with printed material. To supply videos, YouTube was and still is the most used website ever, since the spread of the internet in the 1990s. In this context, the use of videos in the English language classroom has long been the focus of many research projects.

Although using YouTube videos in the English classroom is not uncommon, a course-specific channel with playlists created to supplement the course book and the curriculum is unprecedented in the literature. This particular study focuses on the use of a YouTube channel specifically designed for the Academic Speaking Skills course, which is offered to about 1200 students every semester at Middle East Technical University. The study aims to find out the reflection of students on the use of the extra course material on this channel. The Academic Speaking Skills course is offered by the Modern Languages Department (MLD) to students of all departments as a required course. The idea of launching a channel first came up as a result of the questionnaire sent out to the instructors teaching the course which was investigating the weaknesses of the already available Academic Speaking course materials and the course in general. This mini-scale needs analysis revealed a need for video materials to supplement the course. Hence, to compensate for the missing video materials component of the course, a YouTube channel with 15 different playlists was launched to be used as supplementary course material in Academic Speaking Skills. The videos comprise course-related content input, sample presentations and tasks displaying the expectations of the course, listening and note taking practice exercises, in addition to conversation opening content. Throughout the two semesters that the instructors were asked to use the material on the channel, instructors were given guidance as how to incorporate the channel into the already existing course content on a regular basis during departmental meetings. The video input that students could also access, that is the animated input videos, listening soundtracks, brainstorming or schemataactivating videos were created parallel to the themes of the course book, "The Compass' by Nuans Publishing House. The primary aim was to meet the needs of the students who were expected to present in a specific predetermined structure, which is unprecedented in the already available videos online. Thus, when preparing the videos and developing the channel, the intention was firstly, to clarify the expectations of the rubrics used to evaluate the presentations. The assumption was that the expectations of the presentations required in the course were better 
understood by the students when example presentations were played and analyzed in class, and evaluated with a critical perspective in classroom discussions. It was considered to be much easier to clarify the expectations from the students with the sample presentations available on this course specific channel. The secondary aim of the channel was to provide input and content-related videos which are likely to initiate and facilitate debate and discussions in this speaking-oriented course. This paper focuses on students' perceptions on the effectiveness of the creation, selection and use of these supplementary course material videos in the Academic Speaking Skills course. In this paper, firstly, an overview of the use and perception of videos, and specifically YouTube in the language classroom research will be given; next, the methodology of the research of this study will be described; and finally the results of the research will be discussed. This research is especially significant since the educational literature has an abundance of research on the use of videos or YouTube, yet, it lacks studies on YouTube channels designed to supplement course material in a language skills course. This unexplored area will be the main contribution of this study to the existing literature.

\subsection{Videos in language classrooms}

The prominent role of information technology in education on a large scale is undeniable. Information technology applications in education are diverse. Online video sharing platforms are becoming more pervasive every day, especially in language education. The European Commission, in its report that dates back to even 2013 , states that the number of schools that make active use of online networks is increasing steadily. Not surprisingly, this progressively acquired role of educational technology has captured the attention of practitioner teacher researchers. The study that dwells on the effect of these new online applications on achievement reports that although such technology, per se, would not suffice to enhance student achievement, with the right practice of incorporating technological tools, a positive difference can be made in the quality of education (OECD as cited in Comi, Argentin, Gui, Origo, \& Pagani, 2017),

Video strips were used in language education as early as World War II (Hovland, Lumsdaine \& Shefield, 1949). Ever since then, videos have become a major technological tool in language education. For example, Perez, Peters, and Desmet's (2017) study focuses on the effect of exposure to YouTube videos on L2 vocabulary acquisition. In their research on vocabulary learning through video viewing they report that participants' vocabulary size was directly related to the inferencing skills they developed by using the context in the videos they were exposed to. Similarly, Chun and Pluss (1996) studied the effects of multimedia annotations on vocabulary acquisition, bearing in mind that vocabulary acquisition has revealed that 'words associated with actual objects or imagery techniques are learned more easily', in their study in which 160 German students participated by using a program which helped students with guessing the new words by videos in addition to pictures. The positive effect of the visuals effect on learning vocabulary was and has been undeniable. 
Although vocabulary is the mainstream focus of much English Language teacher research, comprehension in general is enhanced when using videos in the language classroom. Mohsen (2016) elaborates on the use of video simulations to examine the students' comprehension and incidental vocabulary learning. Forty-three Arab adult learners, in their study, participated in a virtual knee surgery simulation by dragging various surgery devices, which were shown in the clip, over the knee of a patient. Interactive video 'games' are found to be significantly influential in the participants' comprehension in addition to vocabulary learning.

Studies have also focused on the relationship between using videos as educational tools and public speaking, which is directly relevant to the focus of this current study. Lee and Liang (2012) investigated the effect of great speech footages (available online) in relation to students' cognitive speech difficulties in public speaking. They state that videos do play a significant role in teaching public speaking, since today, literacy comes in varying forms, and is not limited to text-based literacy only. Even more, it is reported in their article that observation of presentations helps students understand the constructs of public speaking, such as 'hand and arm movements, head nods, head gestures, facial expression, dress, posture, the details of the environment'. Speech delivery, too, can be discussed by students through these videos. About half of the playlists of the Academic Skills Course YouTube channel are allocated to student presentations, bearing in mind the same rationale. They also emphasize the importance of the selectiveness of the instructor when choosing videos, in their words: 'when used at the right time and place, audiovisuals exert positive contributions to language learning'. Today, the selection of videos can be categorized in playlists which also helps students and teachers to make reference to the videos easily, since playlists can be given self-explanatory names of their content, such as 'Discussion Videos for the Mind Theme' or 'Science and Technology Presentations', or 'Presenting Numerical Data' in the Academic Speaking Course YouTube channel (http://bit.ly/211youtube).

In their article about YouTube and language learning, the researchers refer to some weak features of the videos available online, such as poor sound quality and pronunciation mistakes and slang language used (Ghasemi, Hashemi, \& Bardine, 2011), which makes it clear why a channel with supplementary materials can benefit students much more than making use of already available videos on YouTube. The instructor can prepare the channel with decent and good quality videos that are directly relevant to the course being taught. Ghasemi, Hashemi, and Bardine refer to the ease of adaptability of sources on YouTube, which is very significant since the profile of students at any educational institution is changing with the penetration of new information technologies to educational centers every day.

Another characteristic of YouTube videos is that they can be co-creative. Jenkins and Dillon (2013) report their study in which they have students explore a concept through student presentations broadcast on YouTube and have their students do peer critique. The students were expected to work in groups of four and present for 1-4 minutes. It is reported that the collaborative knowledge they created by receiving constructive feedback from each other regarding their presentations proved to be very 
beneficial. Similarly, some of the videos in the Academic Speaking Skills course channel were co-created. Students either worked in groups to shoot commercials, to add voiceover on the muted movie scenes, or presented in groups.

Yet another asset of YouTube is that it is cost-effective. There is no limit as to the memory one can use online and viewing the videos is for free. Yagci (2014) in his article refers to this feature, and adds that YouTube is also a ubiquitous portal that is accessible anytime and anywhere. That is, for students to access the videos is very cheap and easy.

Although this paper studies the perception of a course-specific YouTube channel to serve a speaking course, the literature refers to its benefits to develop other skills, as well. Styati (2016) analyzed the effects of YouTube tutoring on developing students' writing skills and found out that there is a significant difference between the students who were taught by using YouTube videos and those who were taught by using pictures. Interestingly, according to this research, the video-tutored students were found to have a lower writing performance. Apparently, visual and oratory skills are directly relevant to videos, and can be enhanced via YouTube, yet the same may not apply to other language skills, depending on the context and the practice.

YouTube videos can accommodate different learning styles, too. Depending on the abundance of strategies they are used with, they can appeal to students who have an infinite number of individual differences from one another. Duffy (2008) in his article explores how instructors can incorporate YouTube-like tools into the shifting pedagogical paradigm by emphasizing the changing nature of students as stakeholders. Duff defines students today, as 'absorbing information quickly', even at 'twitch speed'. YouTube meets the need for on-demand access to the media of the 'Nintendo generation', accommodating to different learning styles in its social space because repetition of viewing the videos, using the free-frame technique, or developing listening or note-taking techniques at one's own pace is possible with online videos. The 'sound off' technique lends itself to focus on body language, gestures, and visuals, as the videos can be 'segmented' and used to draw attention to the pronunciation of particular words; that is, varying teaching techniques are possible to address different needs. These techniques sit well with the understanding of the profile and context of the young generation in the digital age. Hwang (2010), too, dwells on the most and least used strategies by students when note-taking information, while watching YouTube videos. In Hwang's study, the videos were mostly used to empower students' listening proficiency. The results revealed that pause and rewind buttons on YouTube sites serve as functional and effective tools for learners when they need to make use of the concrete facilities in order to pick up particular details in a video.

Apparently, the positive spin-off of the ever-changing technological advancements is hardly a novel concept. Yet, in the literature, the research focusing on designing a channel to supplement a course is rare. Kelsen's (2009) research is actually, one of those rare studies. Kelsen (2009) reports, that in the university English language course, the supplementary materials used from YouTube were found to be interesting, 
relevant and beneficial. However, the students in Kelsen's study rated YouTube supplementary materials less motivating when used in class compared to when used outside class. While the supplementary use of YouTube videos is limited, referring to these videos for content is more common. To provide solutions to the increasing demand for learning resources, YouTube has proven to be very effective. Alwehaibi (2015) in his research compared the difference between giving traditional content instruction in the classroom and giving it via YouTube, investigating 'the impact of integrating YouTube technology into EFL instruction on enhancing EFL college students' content learning'. He concluded that the outcome of the group of students who were given instruction via YouTube videos is promising for the integration of video technology.

As can be gathered from the literature review above, YouTube is a viable tool in education, and it seems to have penetrated into the classroom of the language teacher already as a motivational and inspiring tool both to develop strategies or to convey content.

There is no study in the literature which has analyzed the perceptions of the students of a course-specific YouTube channel with supplementary material videos for an academic speaking skills course. Therefore, this study, is expected to make a significant contribution to the literature discovering students' experiences and perceptions towards the use of the aforementioned channel. Moreover, this study opens new horizons for researchers, educators and instructors by triggering thoughts on new possibilities of using videos in the English classroom.

With this aim, this study revolves around three research questions which are:

1. What are the students' experiences and opinions on the use of a YouTube channel used in the Academic Speaking Skills course?

2. What are the students' insights on the effectiveness of videos used in the YouTube channel which is used in this course?

3. What are the students' suggestions and comments about using this YouTube channel/ these videos in the Academic Speaking Skills course?

\section{Method}

\subsection{Purpose of the study}

This study aims to investigate students' experiences and insights on the use of YouTube videos in a language education setting, in the Academic Speaking Skills course at Middle East Technical University. With this aim, it was designed as a 'survey study'. The research was conducted with 70 students enrolled in the compulsory Academic Presentation Skills course offered by the Department of Modern Languages to students from varying disciplines. They were asked to fill out a paperbased survey and/or an online survey through the Google Forms at the end of the course to investigate their experiences and perceptions on the drawbacks and benefits of the aforementioned YouTube channel. 


\subsection{Context of the study}

The study was conducted in the Academic Speaking Skills course in the, 2016-2017 Academic year at one of the most prominent universities in Turkey, Middle East Technical University. The course in which this study was conducted is a compulsory speaking-oriented course designed with the aim of equipping students with the essential speaking skills they need to cope with the English language as a medium of instruction. The course revolves around two main focuses: academic speaking and presentation skills. To this end, the course offers a theme-based approach where all four skills are integrated to foster various speaking opportunities. Since the main focus of the course is on speaking, the listening, reading and writing tasks serve as a springboard to either generate or to complement speaking tasks. The emphasis is put on variety, language skills and the balance between input and practice throughout the course aim to help students become more confident, autonomous and competent speakers of English. The course is offered by about 20 instructors each semester based on the same course syllabus.

\subsection{Research design}

This study was designed as a survey study in which investigators administer a survey to a sample or population to describe the attitudes, opinions, behaviors, or characteristics of the population (Creswell, 2012). Its focus is directed more toward learning about a population and less on relating variables or predicting outcomes. It is used to describe trends, determine individual opinions, and provide useful information to evaluate course materials (Creswell, 2012; Fraenkel, Wallen, \& Hyun, 2012). This study is a type of survey study since it examines the participants' experiences and opinions about the use of a YouTube channel in a language course. Specifically, this is a type of cross-sectional survey research design in which the data is collected at one point in time. Throughout the semester, a YouTube channel was used as a course supportive tool. The presentations, speaking task samples, animated videos, and extra listening practice material were prepared by the course instructors and students, and were uploaded to the channel. This specifically designed channel on YouTube in this study can be reached at https://www.youtube.com/user/seherbalbay.

\subsection{Participants of the study}

The set of participants in the study were mostly second year students from various departments who were taking the required course offered by the Department of Modern Languages (Freshman English) at Middle East Technical University, Ankara, Turkey. The participants included 70 students (28 females, 42 males). They were selected based on the convenience sampling method, a type of nonprobability sampling method based on the criteria of being readily available, accessible, and willingness to participate (Creswell, 2012). The participants were informed that their participation was voluntary. 
In accordance with the demographics of the participants, their age distribution is visualized in Figure 1. As can be seen in the figure below, they were mostly between the ages 21-24, followed by 17-20.

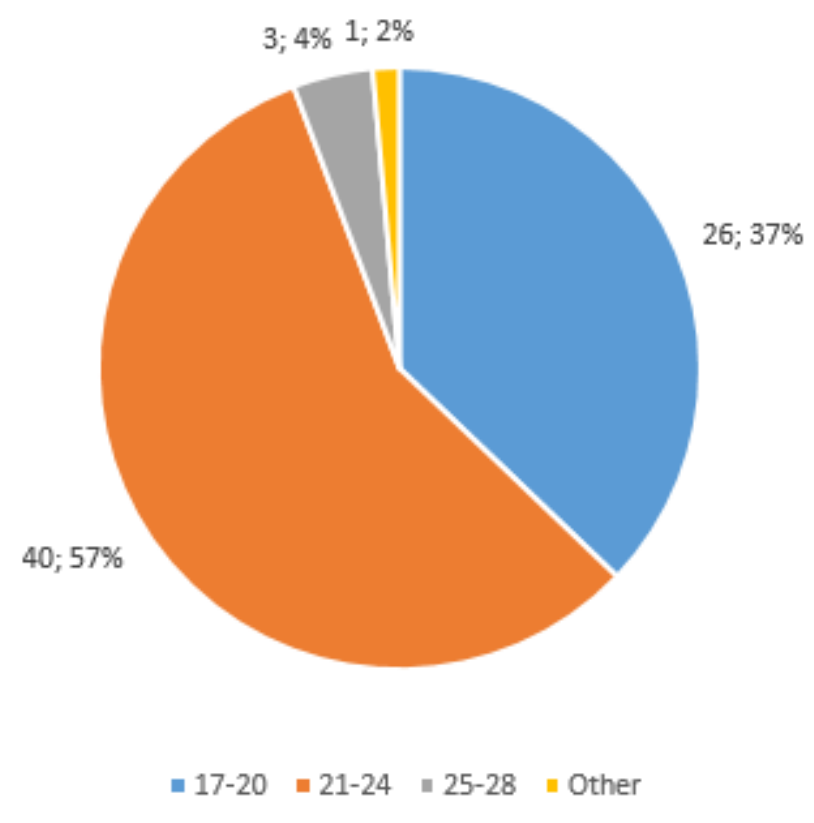

Figure 1. Age distribution of the participants

Of the 70 students, the majority of them were males $(70 \%, n=42)$ while 28 of them (40\%) were females. They were from different disciplines; the majority (69\%) were from the Faculty of Engineering, followed by Arts and Sciences (16\%), Economy and Administrative Sciences (10\%), and lastly the Faculty of Education (6\%). The subject characteristics including age, gender, and faculty information were presented in detail to provide and enhance external validity.

\subsection{Data collection and analysis procedure}

The participants were asked to fill out a paper-based survey (see Appendix) and/or online via Google Docs at the end of the course on their perceptions on the drawbacks and benefits of the YouTube channel specifically designed for the Academic Speaking Skills course. The data was collected from 70 volunteering students, and then analyzed with both descriptive statistics and deductive content analysis. The descriptive statistics were conducted via IBM SPSS version 23. Deductive content analysis was conducted by two-researchers together to provide the correct interpretation.

Regarding the trustworthiness of the study, ethical rules were followed throughout the study in that, all of the participants were informed about the aim of the study, treated with respect, and their identities were kept confidential. The instrument used to collect data was reviewed by subject matter experts to ensure content validity. The following section presents the findings of this study. 


\section{Results}

\subsection{Students' experiences and opinions on the use of YouTube channel}

The findings of this study indicated that $41 \%$ of the participants $(n=29)$ used YouTube/YouTube channel before in some course other than the Academic Presentation Skills course, while the remaining did not use it class at all. Students also added that they used YouTube before other than this course in the following courses: Calculus $(n=12)$, Physics $(n=9)$, language courses $(n=2)$, computer programming courses $(n=2)$, mechanical engineering courses $(n=4)$, chemistry $(n=3)$, industrial engineering courses $(n=1)$, and aerospace engineering courses $(n=1) .77 \%$ of them stated that they watched YouTube videos every day outside class, $16 \%$ stated 'rarely' and 7\%, 'only at weekends'. Their reasons to watch YouTube videos varied. Of those students, 58\% of them watched YouTube videos for entertainment, 37\% for educational purposes, 26\% for improving their English level, and the remaining 8\% for other purposes which includes listening to music $(n=3)$, watching videos $(n=3)$, being updated about news $(n=1)$, and other educational purposes $(n=3)$. The majority of the students $(90 \%, n=63)$ think that the YouTube channel used in the Academic Presentation Skills course was beneficial. The descriptive statistics about the items in the survey are provided in Table 1.

Table 1. Students' Experiences and Opinions about the Use of YouTube Channel

\begin{tabular}{lcc}
\hline Likert-type Items & M & SD \\
\hline 1- Discussing the YouTube videos made class more interesting. & 1 \\
2- The YouTube videos used were relevant to course content. & 4.1 \\
3- Using YouTube in class has been more effective than looking at slides. & 4 \\
4- The YouTube videos in class motivated me to practice presenting. & 3.8 \\
5- The YouTube videos in class motivated me to watch more presentations than the ones in & 4 \\
the playlists. & 1.12 \\
6- The YouTube videos used in class increased my participation in the classroom. & 4 \\
7- Using YouTube videos increased my comprehension of the lesson content. & 4.1 \\
8- Watching 211 related YouTube videos in class had beneficial effects on developing my & 3.9 \\
presentation skills. & 1.22 \\
9- YouTube videos are a good source for practicing listening comprehension. & 1.12 \\
10- The videos we were asked to watch helped me improve my pronunciation and \\
$\begin{array}{l}\text { intonation. } \\
\text { 11-If I were a teacher, I would use a YouTube channel/videos in my courses. }\end{array}$
\end{tabular}

According to the results, as seen on table above, descriptive statistics indicated that students' perceptions of the YouTube videos making the class more interesting has a mean score of 4.00 over 5.00 and standard deviation of 1.00 . The findings also showed that their perceptions of the YouTube videos used was relevant to the course content $(\mathrm{M}=4.1, S D=1.13)$, the efficiency of YouTube videos over slides $(\mathrm{M}=4.00, S D=1.1)$, the motivation factor of the videos to practice presenting $(\mathrm{M}=3.8, S D=1.22)$, the motivating factor of the videos to watch more videos on the playlist/channel $(M=4.00$, $S D=1.1)$, the increase in their participation in class by the videos $(\mathrm{M}=4.00, S D=1.22)$. 
In addition, the findings indicated that according to their perceptions of the videos, the increase in their comprehension of the lesson content has a mean score of 4.10 over 5.00 and standard deviation of 1.16 , whereas the benefit of the videos on the development of their presentation skills was $(\mathrm{M}=3.90, S D=1.12)$. Being a good source for practicing listening comprehension was $(\mathrm{M}=4.00, S D=1.00)$, the support by the videos to improve their pronunciation and intonation $(\mathrm{M}=4.00, S D=1.10)$, and the intent to use YouTube channel/videos in the courses if they were the teacher $(M=4.00$, $S D=0.90)$.

\subsection{Students' insights on the effectiveness of videos used on the YouTube channel}

Regarding students' insights on the effectiveness of videos on the YouTube channel used in the Academic Presentation Skills course, in relation to the second research question, both most favored videos and overall evaluation of the videos were examined. The findings about the most favored five videos were presented in Table 2 with the percentage values.

Table 2. Students' opinions about the most effective five videos/playlists

\begin{tabular}{ll}
\hline Videos & Percentage \\
\hline Discussion videos & $\% 9$ \\
Unit 1 - Speech anxiety & $\% 5$ \\
Unit 1 - Magic Pill Erases Bad Memories video & $\% 8$ \\
Unit 2 - Good and bad examples of Graffiti on METU campus & $\% 13$ \\
Unit 2 - Preparing slides & $\% 13$ \\
Unit 2 - Life after death by PowerPoint & $\% 10$ \\
Unit 2 - Graffiti of Banksy & $\% 4$ \\
Unit 3 - Introduction and Conclusion examples from TED videos & \\
Student Presentations & $\% 7$ \\
Unit 3 - Expensive wine is for suckers & $\% 12$ \\
Marketing presentations playlist & $\% 8$ \\
Science and Technology presentations playlist & $\% 10$ \\
Final presentations playlist & \\
\hline
\end{tabular}

In terms of their opinions about the five most effective videos/playlists, students' responses varied. Among discussion videos, the videos titled 'Presenting Slides' and 'Life After Death by PowerPoint' were the highest percentages. Similarly, the video titles Marketing Presentations Playlist among student presentations was a higher percentage of all the student presentations. The findings clearly indicated that, there is no consensus about the most effective videos among the students.

With regard to overall evaluation of the videos on the YouTube channel, Table 3 displays the findings retrieved from 63 students' responses.

Table 3. Students' opinions about the videos used in YouTube channel 


\begin{tabular}{lcc}
\hline Name of the Video & M & SD \\
\hline Unit 1 - Speech anxiety & 4.2 & .87 \\
Unit 1 - Magic Pill Erases Bad Memories & 4.1 & .84 \\
Unit 2 - Good and bad examples of Graffiti on METU campus & 4.6 & .83 \\
Unit 2 - Preparing slides & 4.4 & .89 \\
Unit 2 - Life after death by PowerPoint & 4.3 & 1.1 \\
Unit 2 - Graffiti of Banksy & 4.5 & .9 \\
Unit 3 - Introduction and Conclusion examples from TED videos & 4.7 & .86 \\
Unit 3 - Expensive wine is for suckers & 4.4 & .93 \\
Student Presentations - Marketing presentations & 4.4 & .85 \\
Student Presentations - Science and Technology presentations & 4.5 & .89 \\
Student Presentations - Final presentations & 4.4 & .84 \\
\hline
\end{tabular}

According to descriptive statistics, students' opinions about the effectiveness of the video titled Unit 1- Speech Anxiety has a mean score of 4.2 and standard deviation of .87, Unit 1 -Magic Pill Erases Bad Memories (M=4.1, SD=.84), Unit 2 - Good and bad examples of Graffiti on METU campus $(\mathrm{M}=4.6, S D=.83)$, Unit 2 - Preparing slides $(\mathrm{M}=4.4, S D=.89)$, Unit 2 - Life after death by PowerPoint $(\mathrm{M}=4.3, \mathrm{SD}=1.1)$, Unit 2 Graffiti of Banksy ( $\mathrm{M}=4.5, S D=.9)$. The findings also indicated students' opinions about the effectiveness of the video titled Unit 3 - Introduction and Conclusion examples from TED videos has a mean score of 4.7, and a standard deviation of .86, Unit 3 - Expensive wine is for suckers ( $\mathrm{M}=4.4, S D=.93)$. Among the videos of students' presentations, the video titled Marketing presentations has a mean score of 4.4 and standard deviation of .85, Science and Technology presentations $(\mathrm{M}=4.5, S D=.89)$, and Final presentations was $(\mathrm{M}=4.4, S D=.84)$.

\subsection{Students' suggestions and comments about using YouTube channel/videos}

In order to have a better understanding of students' insights on the use of YouTube videos, students were asked about their extra suggestions and/or comments in relation to the third research question. Of the participants, only 8 students made extra suggestions and/or comments. Their positive feedback or comments included "I liked it a lot. It's a good idea.", "I think usage of YouTube is relaxing", and "It was so beneficial. I hope teachers should use it more recently." In regard to their comments or suggestions, one student suggested that "Videos can be more professional. Final presentations can be filmed with professional cameras so that they can be analyzed easily." On the other hand, another student wrote "Examples can be divided into good models and just sample presentations." Other comments or suggestions included "More student presentations may be uploaded.", "There can be more presentations which are presented by students that can be videotaped", "Examples can be divided into examples and non-examples.", and "It would be nice if there were more examples of presentations (especially about average presentations)". Overall, the findings indicated that students mostly liked and benefited from the use of YouTube channel/videos in the Academic Presentations Skills course. They further asked for 
the categorization of professional and average student presentation videos as 'models' and 'examples', etc. The next section of this paper includes the discussion and summarization of the results of this study.

\section{Discussion and Conclusion}

Although the literature includes a great deal of research reporting the benefits of using YouTube videos in the language classroom, studies on the perceptions of teachers and students are rare, and a study on custom-made playlists and a channel devoted to a course is unprecedented. The results of the study prove that it is an undeniable fact that university students today are already very familiar with YouTube, they watch videos for entertainment reasons and even when not required by instructors for learning and self-development reasons. The results of the research in this paper, too, agree with the general overview of the 'digital generation' whose resource for learning is primarily the online websites. Apparently, it is not uncommon for university students today to use YouTube videos in their courses. For the Academic Speaking Skills course, students definitely benefited from the videos because they helped bring about discussion topics in class by adding variety into course material which used to be merely the course book or slides. Moreover, the channel's videos encouraged students to participate in class discussions. Motivation is one of the major contributions of the online material in general, which applies to the context of this study, too. Also, the videos clarified the course content and enabled user-friendly access to the new listening material prepared for the course. Last but not least, the student presentation videos were very helpful in clarifying the objectives of the expected presentations in the course.

One of the most important benefits of course material that is accessible online is that it helps students become autonomous. The results of the study clarify that students actively utilize this particular technology for learning outside the classroom too, which may change the teachers' role in language and skills classrooms. In the context discussed, teachers still have a critical role to play. They make use of the YouTube playlists mentioned or refer their students to those playlists, hence promote autonomous learning with technology outside the classroom. Medaukali (2015) emphasized the importance of the availability of the online video material. Especially for extra listening and note-taking practice, the open access listening materials on the channel were welcome by the students, too. This is actually, the aspect of YouTube videos that appeals to different learning styles, lending itself to be used at students' own pace (Duffy, 2008), to enhance different skills, even to promote writing as mentioned by Styati (2016).

Yagci (2014) emphasized the importance of low costs of using online videos too, which is what made the channel not only user-friendly but also 'owner-friendly'. The channel was perceived to be accessible easily by students due to the fact that they were not required to $\log$ in to YouTube or subscribe to the channel. The channel is open to all. Ma (2017) refers to this feature of mobile learning technologies by defining 
them as a 'lens' for students with which they capture the 'personalized, unique, contextual and ubiquitous nature of mobile language learning'.

According to students' perceptions, the most effective videos vary. There are animated input videos and there are moviemaker videos made up of pictures and music only, there are student presentations, and there are also already available videos on YouTube that are not created for the course. This implies that no single genre of videos stands out as being the most effective, and all the types were perceived to be beneficial, relevant and interesting by the students. They were motivated especially by the 'student presentations'. The channel lets students see other students present thanks to the 'collaborative and co-creative' nature of online videos (Jenkins \& Dillon, 2013). Some of the videos on the channel are of group work tasks, such videos are called 'participatory videos' in the literature (Yan, 2012). They are the products of a process in which participants work together. This contributed to the students' team building and community building which are of utmost importance in a speaking skills class.

Mobile technologies are no longer a new form that mediates people's language learning, but their tailored use to develop certain skills or to develop new course material is an emerging advance in education. The channel is becoming even more popular every day and more videos are being added. Its content is shaped by the constant feedback received from students and teachers of the course. Overall, the channel provided effective course material that the participants of the study appreciated. This study may open new horizons and trigger creative thought for future uses of YouTube in the language classroom.

One limitation of the current study may be that it was conducted in the first year the channel was launched. In the coming years, with more innovative ideas the channel will most probably serve its purpose to a greater extent. Further study may focus on making use of the properties that YouTube lends itself to, such as designing a task in which students can write comments about each other's performances or products. Future research can also focus on the effectiveness of online training platforms to enhance both language skills and willingness of learners to engage in self-directed use of technology. How to make use of such supplementary material YouTube channels in language teaching and skills developing, can be explored to a greater extent in future research.

\section{References}

Alwehaibi, H. O. (2015). The impact of using Youtube in EFL classroom on enhancing EFL students' content learning. Journal of College Teaching \& Learning (Online), 12(2), 121.

Chun, D. M., \& Plass, J. L. (1996). Effects of Multimedia Annotations on Vocabulary Acquisition. The Modern Language Journal, 80(2), 183-198. Retrieved October 09, 2017, from http://www.jstor.org/stable/328635

Comi, S. L., Argentin, G., Gui, M., Origo, F., \& Pagani, L. (2017). Is it the way they use it? Teachers, ICT and student achievement. Economics of Education Review, 56, 24-39. 
Creswell, J. W. (2012). Educational Research: Planning, Conducting, and Evaluating Quantitative and Qualitative Research. Pearson Education, Inc.

Duffy, P. (2008). Engaging the YouTube Google-eyed generation: Strategies for using Web 2.0 in teaching and learning. Electronic Journal of E-learning, 6(2), 119-130.

Fraenkel, J. R., Wallen, N. E., \& Hyun, H. H. (2012). How to design and evaluate research in education (Vol. 7). New York: McGraw-Hill.

Ghasemi, B., Hashemi, M., \& Bardine, S. H. (2011). UTube and language learning. ProcediaSocial and Behavioral Sciences, 28, 63-67.

Hovland, C. I., \& Lumsdaine, A. A. (2017). Experiments on mass communication. Princeton University Press.

Hwang, J. L. (2010). University EFL Students' Learning Strategies On Multimedia YouTube. In EdMedia: World Conference on Educational Media and Technology (pp. 3611-3620). Association for the Advancement of Computing in Education (AACE).

Jenkins, J. J., \& Dillon, P. J. (2013). Learning through YouTube. In Ferris, S.P. \& Wilder, H.A. (eds) The plugged-in professor: Tips and techniques for teaching with social media. Oxford, UK: Chandos Publishing.

Kelsen, B. (2009). Teaching EFL to the iGeneration: A survey of using YouTube as supplementary material with college EFL students in Taiwan. Call-EJ Online, 10(2), 10-2.

Lee, Y. J. J., \& Liang, J. C. (2012). Using video technology to diagnose EFL students' cognitive learning difficulties in public speaking. Procedia-Social and Behavioral Sciences, 64, 671680.

Ma, Q. (2017). A multi-case study of university students' language-learning experience mediated by mobile technologies: a socio-cultural perspective. Computer Assisted Language Learning. DOI: 10.1080/09588221.2017.1301957

Medaukali, F. (2015). Developing EFL Learners' Listening Comprehension through YouTube Videos: A Case Study of Second Year Students at Mohamed Kheider University of Biskra. (Unpublished Master Thesis) Mohamed Kheider University, Biskra

Mohsen, M. A. (2016). The Use of Computer-Based Simulation to Aid Comprehension and Incidental Vocabulary Learning. Journal of Educational Computing Research, 54(6), 863884. DOI: $10.1177 / 0735633116639954$

Perez, M. M., Peters, E., \& Desmet, P. (2017). Vocabulary learning through viewing video: the effect of two enhancement techniques. Computer Assisted Language Learning, 1-26. DOI: $10.1080 / 09588221.2017 .1375960$

Styati, E. W. (2016). Effect of YouTube Videos and Pictures on EFL Students' Writing Performance. Dinamika Ilmu, 16(2), 307-317.

Yagci, T. (2014). Mobile Social Media Challenges Digital Natives in EFL Learning. Journal of Educational \& Instructional Studies in the World, 4(4).

Yang, K. (2012). Participatory video and reflexivity. The experiences of eight adult learners. Unpublished doctoral dissertation, McGill University, Montreal.

\section{Appendix A. Survey on the use of 211 YouTube Channel}

D1. Which department are you studying at?

D2. How old are you? 
D3. What is your gender?

Female

$\square$ Male

A1. Have you used YouTube before in any course other than this one?

Yes

$\square$ No

A1.1. If YES, in which course(s)?

A2. How often do you watch YouTube videos outside class? *

O Every day

O Only at weekends

O Rarely

O Never

O Other:

A3. Why do you usually watch YouTube videos? (You may choose more than one answer) *

O For entertainment

O To improve my English

O To improve my English

O Other:

A4. Do you think the YouTube channel used in this course was beneficial? *

O Yes

O No

A4.1. If YES, in which ways? (You may choose more than one answer)

O It made the expectations of the tasks clear in my mind.

O It made me aware of what not to do in the required tasks.

O It gave me ideas about possible topics for the required tasks.

O It gave me ideas about possible organization patterns for the required tasks.

O I was motivated thinking that my performance was not much different from the examples on YouTube.

O Other: 
A4.2. If the YouTube channel was not beneficial for you, why not? (You may choose more than one answer)

O I was not sure which playlist to look at.

O I wasted my time looking at examples.

O I thought all the examples were good examples.

O Other:

Section 2: Please rate the following statements based on your agreement/disagreement level considering your experiences and opinions on the YouTube channel you were referred to in 211 (1: Strongly disagree, 2: Agree, 3: Neutral/Undecided, 4: Agree, 5: Strongly agree).

\begin{tabular}{|c|c|c|c|c|c|}
\hline \multirow{2}{*}{$\begin{array}{l}\text { S1. Discussing the YouTube videos made class more interesting. } \\
\text { S2. The YouTube videos used were relevant to course content. }\end{array}$} & 1 & 2 & 3 & 4 & 5 \\
\hline & & & & & \\
\hline $\begin{array}{l}\text { S3. Using YouTube in class has been more effective than } \\
\text { looking at slides. }\end{array}$ & & & & & \\
\hline $\begin{array}{l}\text { S4. The YouTube videos in class motivated me to practice } \\
\text { presenting. }\end{array}$ & & & & & \\
\hline $\begin{array}{l}\text { S5. The YouTube videos in class motivated me to watch more } \\
\text { presentations than the ones in the playlists. }\end{array}$ & & & & & \\
\hline $\begin{array}{l}\text { S6. The YouTube videos used in class increased my } \\
\text { participation in the classroom. }\end{array}$ & & & & & \\
\hline $\begin{array}{l}\text { S7. Using YouTube videos increased my comprehension of the } \\
\text { lesson content. }\end{array}$ & & & & & \\
\hline $\begin{array}{l}\text { S8. Watching } 211 \text { related YouTube videos in class had beneficial } \\
\text { effects on developing my presentation skills. }\end{array}$ & & & & & \\
\hline $\begin{array}{l}\text { S9. YouTube videos are a good source for practicing listening } \\
\text { comprehension. }\end{array}$ & & & & & \\
\hline $\begin{array}{l}\text { S10. The videos we were asked to watch helped me improve my } \\
\text { pronunciation and intonation. }\end{array}$ & & & & & \\
\hline $\begin{array}{l}\text { S11. If I were a teacher, I would use a YouTube channel/videos } \\
\text { in my courses. }\end{array}$ & & & & & \\
\hline
\end{tabular}

S12. Put a check next to the most effective five videos/playlists.

\begin{tabular}{|l|l|}
\hline$\square$ & Unit 1 - Speech anxiety \\
\hline$\square$ & Unit 1 - Magic Pill Erases Bad Memories video \\
\hline$\square$ & Unit 2 - Good and bad examples of Graffiti on METU campus \\
\hline$\square$ & Unit 2 - Preparing slides \\
\hline
\end{tabular}




\begin{tabular}{|l|l|}
\hline$\square$ & Unit 2 - Life after death by PowerPoint \\
\hline$\square$ & Unit 2 - Graffiti of Banksy \\
\hline$\square$ & Unit 3 - Introduction and Conclusion examples from TED videos \\
\hline$\square$ & Unit 3 - Expensive wine is for suckers \\
\hline$\square$ & Student Presentations - Marketing presentations playlist \\
\hline$\square$ & Student Presentations - Science and Technology presentations playlist \\
\hline$\square$ & Student Presentations - Final presentations playlist \\
\hline$\square$ & How NOT to make a presentation \\
\hline
\end{tabular}

S13. Please rate the YouTube videos you were referred to in 211 based on how effective you find them.

\begin{tabular}{|l|l|}
\hline Unit 1 - Speech anxiety & $\square$ \\
\hline Unit 1 - Magic Pill Erases Bad Memories video & $\square$ \\
\hline Unit 2 - Good and bad examples of Graffiti on METU campus & $\square$ \\
\hline Unit 2 - Preparing slides & $\square$ \\
\hline Unit 2 - Life after death by PowerPoint & $\square$ \\
\hline Unit 2 - Graffiti of Banksy & $\square$ \\
\hline Unit 3 - Introduction and Conclusion examples from TED videos & $\square$ \\
\hline Unit 3 - Expensive wine is for suckers & $\square$ \\
\hline Student Presentations - Marketing presentations playlist & $\square$ \\
\hline Student Presentations - Science and Technology presentations playlist & $\square$ \\
\hline Student Presentations - Final presentations playlist & $\square$ \\
\hline How NOT to make a presentation & $\square$ \\
\hline
\end{tabular}

S14. Finally, do you have any suggestions about using YouTube channel/ videos in this course?

\section{Copyrights}

Copyright for this article is retained by the author(s), with first publication rights granted to the Journal. This is an open-access article distributed under the terms and conditions of the Creative Commons Attribution license (CC BY-NC-ND) (http://creativecommons.org/licenses/by-nc-nd/4.0/). 